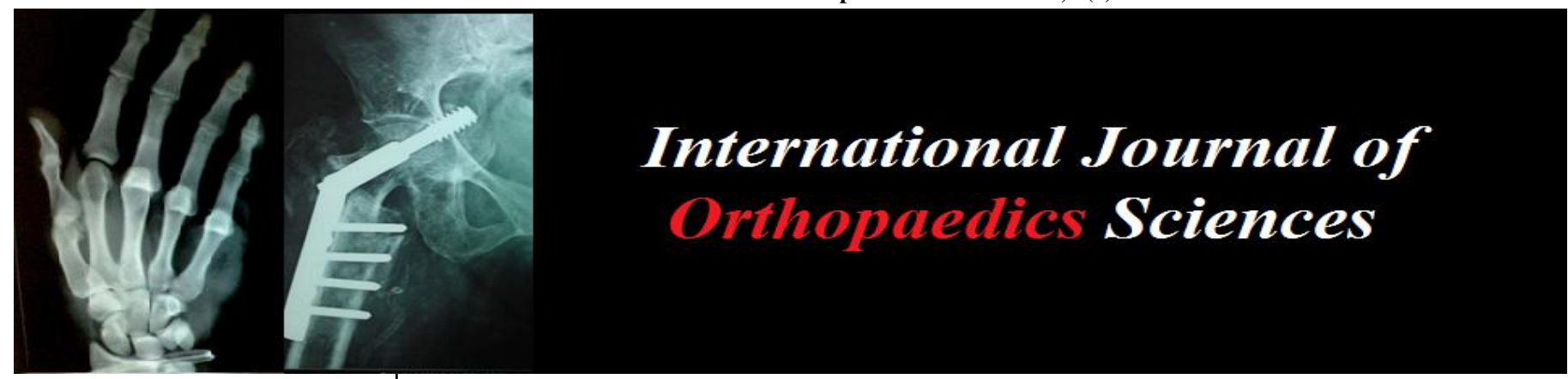

ISSN: $2395-1958$

IJOS 2018; 4(1): 753-758

(C) 2018 IJOS

www.orthopaper.com

Received: 15-11-2017

Accepted: 16-12-2017

Eknath Pawar

Department of Orthopaedics. Grant Government Medical

College and JJ Hospital,

Mumbai, Maharashtra, India

\section{Sandeep Gavhale}

Department of Orthopaedics. Grant Government Medical

College and JJ Hospital,

Mumbai, Maharashtra, India

\section{Arohi Sharma}

Department of Orthopaedics.

Grant Government Medical

College and JJ Hospital,

Mumbai, Maharashtra, India

Ujwal Ramteke

Department of Orthopaedics.

Grant Government Medical

College and JJ Hospital,

Mumbai, Maharashtra, India

Ankit Marfatia

Department of Orthopaedics. Grant Government Medical

College and JJ Hospital,

Mumbai, Maharashtra, India

Correspondence

Sandeep Gavhale

Department of Orthopaedics.

Grant Government Medical

College and JJ Hospital,

Mumbai, Maharashtra, India

\section{Correlation of bohler's angle and role of bone graft in the functional outcome of displaced intra-articular calcaneal fractures}

\author{
Eknath Pawar, Sandeep Gavhale, Arohi Sharma, Ujwal Ramteke and \\ Ankit Marfatia
}

DOI: $\underline{\text { https://doi.org/10.22271/ortho.2018.v4.i1k.110 }}$

\section{Abstract}

Background: Calcaneum is the most common tarsal bone fractured. The treatment is difficult and rehabilitation can be time-consuming, and still the outcome is highly unpredictable. This makes calcaneal fractures a huge socio-economic burden to society. This made us search for a variable, like Bohler's angle, which we could relate with functional outcome in patients with intra articular calcaneal fractures. Material and method: 42 patients who had intra-articular fracture of a calcaneum were selected. All the patients were investigated preoperatively with x-rays and CT scanning. The Bohler's angle was calculated on the lateral radiograph manually with the help of goniometer and a record was prepared for future references. Randomization was done and all patients were managed with open reduction and internal fixation with plate with or without bone graft. Bohler's angle was measured post operatively and at follow up on 4 weeks, 6 weeks, 8 weeks and after 3 and 6 months and 1 year. Assessment of the patient with Functional recovery was done with American orthopaedic foot and ankle score (AOFAS) minimum 6 months after injury.

Result: Our study of 42 calcaneal fractures confirms that there is statistically significant difference between the functional outcome of patients regarding correction of the Bohler's angle obtained during surgery. When Bohler's angle is restored within normal limits, in an operated calcaneus fractures, fewer complications and statistically significant better results were observed. We also confirmed that autologous bone graft is beneficial in achieving and maintaining restoration of calcaneal height and anatomic reduction.

Conclusion: In view of the excellent results obtained with restoration of Bohler's angle, we advocate the use of Bohler's angle as a key to achieve excellent result in displaced calcaneal fracture and also use of autologous bone graft in achieving and maintaining normal Bohler's angle.

Keywords: Calcaneum fracture, Bohler's angle, open reduction and internal fixation, Autologous bone graft, Intra-articular fractures

\section{Introduction}

Calcaneum is the most common tarsal bone fractured. The commonest mechanism of injury is fall from height followed by motor vehicle accidents. Calcaneal fractures, particularly the intra articular ones, are one of the most disabling fractures, with frequent occurrence in young adults ${ }^{[1]}$. The treatment is difficult and rehabilitation can be time-consuming in intra articular calcaneal fractures, and still the outcome is highly unpredictable ${ }^{[2]}$. This makes calcaneal fractures a huge socio-economic burden to society. This made us search for a variable, like Bohler's angle, which we could relate with functional outcome in patients with intra articular calcaneal fractures. Bohler's angle, also written as Bohler angle or Boehler angle, is also called the calcaneal angle or tuber joint angle. The tuber angle of Bohler is indicated by a line drawn from the highest point of the anterior process of the calcaneus to the highest point of the posterior facet and a line drawn tangential to the superior edge of the tuberosity. The normal value for this angle is between $20^{\circ}$ to $40^{\circ}$. A value less than $20^{\circ}$ can be seen in calcaneal fracture. However, a normal Bohler's angle does not exclude a calcaneal fracture ${ }^{[3]}$. The aim of this study is to determine whether restoration of Bohler's angle within normal ranges gives better outcome when compared to the outliers. 


\section{Materials and method}

All patients attending orthopaedic department with calcaneal fracture who met the inclusion criteria were counselled regarding the disease and the study and those willingly consenting to participate in the study were selected. Informed and written consent was obtained from all patients with consent form approved by the Institutional ethical committee. A total of 42 subjects were consecutively recruited for the study.

Inclusion criteria: Age above 18 years and less than 60 years, Displaced intra articular fracture, decreased Bohler's angle, patients who were medically fit for surgery, Exclusion criteria: Pathological fracture, all open fracture, associated compartment syndrome or vascular injury, polytrauma, extraarticular fracture.

All the selected patients underwent routine investigations, was clinically evaluated in detail regarding the mode of injury and treatment taken prior to admission. A detailed examination was done to assess any deformity, associated injuries was noted, if any.

Standard antero-posterior and lateral roentgenographic views of the ankle and CT scan was taken (figure 1). The Bohler's angle was calculated on the lateral radiograph. CT images were evaluated for intra articular commination.

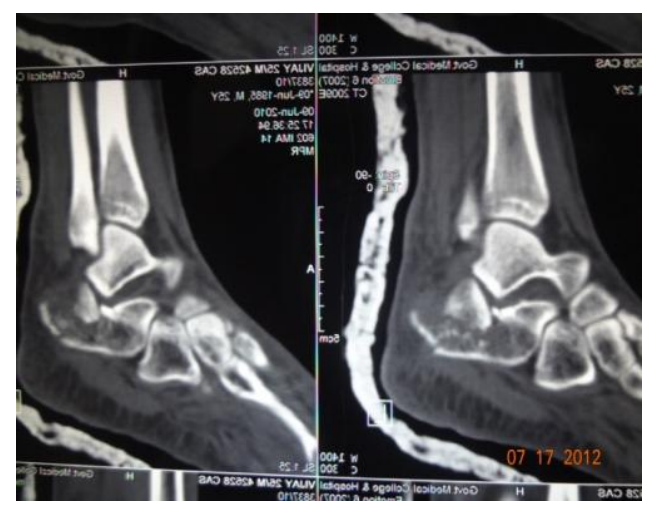

Fig 1: Preop CT Image

Patients were subjected to all relevant preoperative investigations and were taken up for surgery as soon as soft tissue condition allowed and he/she was fit for anaesthesia. Surgery was performed under spinal anaesthesia The average duration from admission to surgery was 8 days. The patients were randomly assigned to two groups, GROUP I with bone grafting and GROUP II without bone grafting. Clinical follow-up examination was performed at 4 weeks, 6 weeks, 10 weeks, 3 months, 6 months and 1 year. All patients were assessed clinically and radiographically with following terms such as tenderness at fracture site, abnormal mobility, infection, pain on movement of ankle joint and anteroposterior and lateral radiographs of the ankle for union of fracture.

On admission all patients were addressed for:

1. Skin condition

2. Deformity

3. Any other associated injuries

4. Fracture morphology

Out of 42, 6 Patients were operated 10 days after injury because of oedema and bad skin condition. Till then limb elevation, magnesium sulphate dressings, immobilization in slab was given.

\section{Fixation}

Patients were positioned in lateral decubitus position on an operating table with a radiolucent carbon part. Pneumatic tourniquet was used in all patients. An extended lateral approach was used (figure 2). The approach was developed as a full-thickness flap. The lateral cortical fragment (bulge fragment) was then hinged away. Subsequently, a good view into the subtalar joint was obtained. The soft tissue flap was held back by K-wires, which were inserted into the talus and lateral malleolus (figure 3). Joy-stick technique with a Schanz screw placed through the tuber calcanei was used to achieve reduction and regain in particular the length and axis. The fractured lateral wall of the calcaneum was gently opened, leaving the fracture fragments within their periosteal envelope. The fragments were elevated; the articular surface was reduced using the articular surface of calcaneum as template. The individually reduced bone fragments were fixed temporarily with $\mathrm{K}$-wires and reduction was confirmed under C-arm (figure 4). In GROUP I patients ipsilateral iliac crest bone grafting was done. It was placed in the defect below articular surface. Bohler's angle was reconstructed and was confirmed under $\mathrm{C}$-arm. After satisfactory reduction, plate was applied and fixation of the plate was done with multiple screws. Particular care was taken to fix the central fragment (posterior subtalar fragment) in a good and stable position.

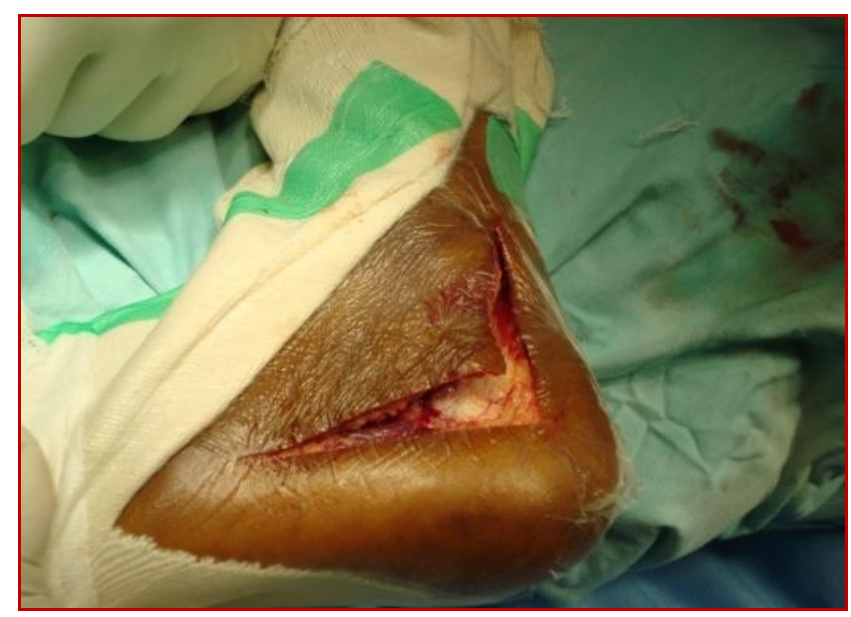

Fig 2: Incision

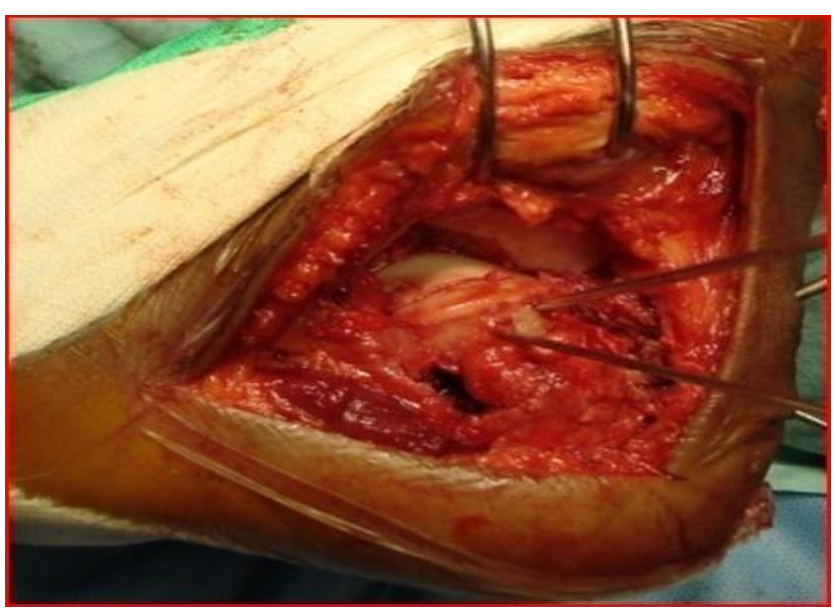

Fig 3: peroneal tendons retracted using $\mathrm{k}$ wire 


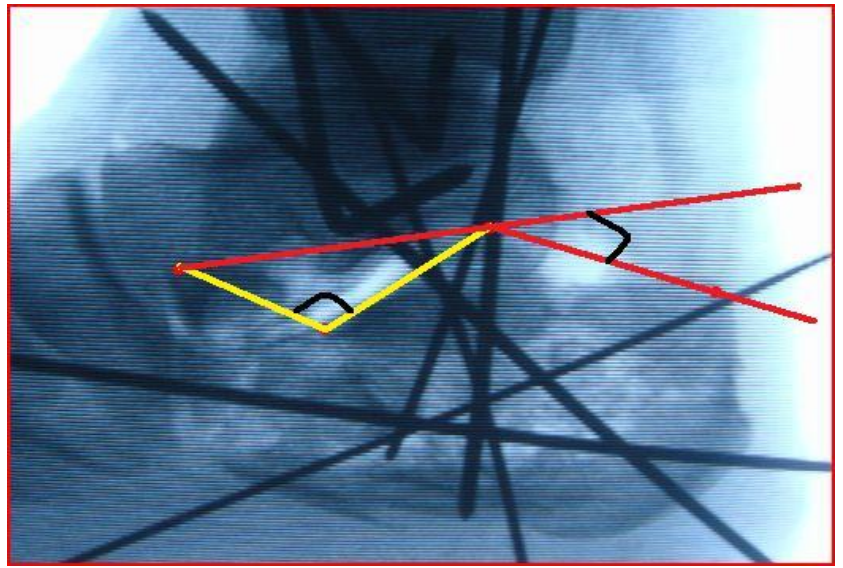

Fig 4: intraoperative C-arm for assessing reduction

\section{Follow up}

\section{A) First follow up - 4 weeks}

1. Radiological assessment (figure 5).

2. Continue knee range of movements and active quadriceps exercises.

\section{B) Second follow up - 6 weeks}

Partial weight bearing with the help of crutches.

\section{C) Third follow up - 8 weeks}

Clinico-radiological assessment. 50\% weight bearing started increased to $75 \%$ after 15 days

\section{D) After 3 and 6month (figure 6).}

Clinico-radiological assessment. Usually fracture unites sufficiently.

Full weight bearing walk.

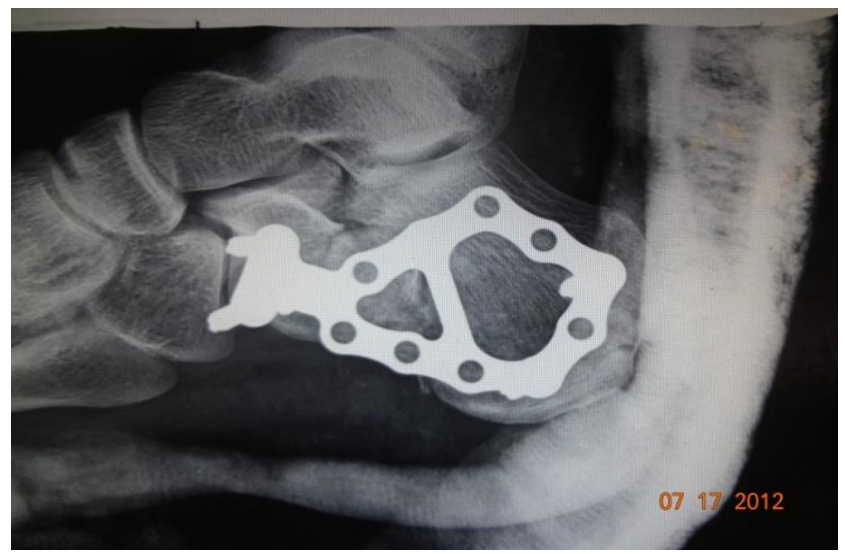

Fig 5: Postop X-ray

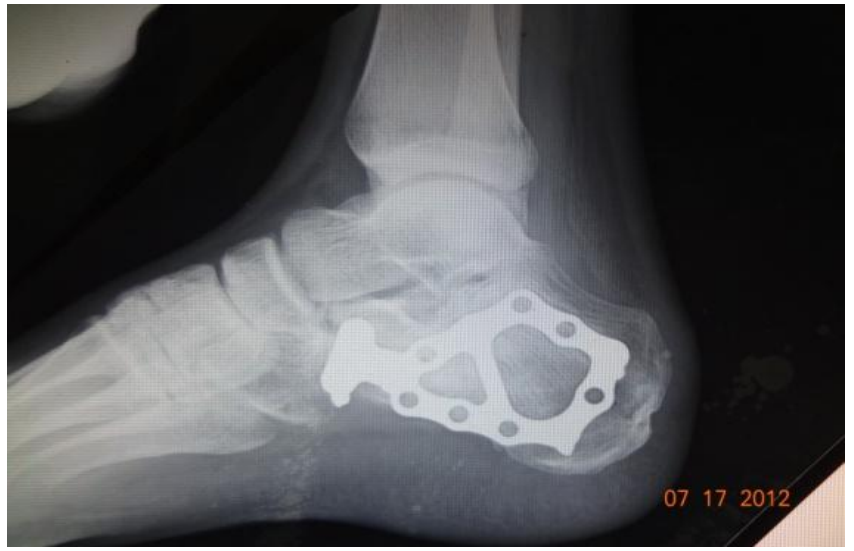

Fig 6: follow up at 6 month

\section{Observation and results}

Our study of 42 calcaneal fractures confirms that there is statistically significant difference in the functional outcome of patients regarding correction of the Bohler's angle obtained during surgery. The population of calcaneal fracture in our study is comparable to other studies. We observed these fractures mainly in age group of 30-40 years (Table 1 and 2), with a mean (SD) for age was 34 years, which were involved in trauma due to fall from height. Calcaneal fractures seen in elder age group were mainly due to abnormal loading patterns on the leg, for example due to fall from height. Majority of our cases were due to direct injuries (Table 3). In case of direct injury pattern soft tissue injury observed was more and we had to wait longer time before taking patient for surgery. We evaluated all fractures clinically for soft tissue injury. We took four $\mathrm{x}$ rays for all patients including anteroposterior, lateral, axial and Broden's view. We classified all fractures according to Essex-Lopresti, which we have found best (Table 4). Since it gives idea about both, mechanism of injury and guideline for further treatment plan. Further it is simple with less inter-observer variation. We operated all of them under Spinal Anaesthesia. The patients were randomly assigned to two groups, GROUP I with bone grafting and GROUP II without bone grafting (Table 5).

\section{Age distribution}

Table 1: Age Distribution $(n=42)$

\begin{tabular}{|c|c|c|}
\hline Age (years) & Group I & Group II \\
\hline $18-29$ & $6(14.28 \%)$ & $9(21.43 \%)$ \\
\hline $30-39$ & $11(26.2 \%)$ & $7(16.67 \%)$ \\
\hline $40-49$ & $2(4.76 \%)$ & $3(7.14 \%)$ \\
\hline $50-59$ & $2(4.76 \%)$ & $2(4.76 \%)$ \\
\hline Total & $21(100 \%)$ & $21(100 \%)$ \\
\hline
\end{tabular}

Amongst age distribution, maximum patients (46.66\%) being in the age group of 30-39 years. The mean (SD) for age was 34 years.

\section{Sex distribution}

Table 2: Sex Distribution $(\mathrm{n}=42)$

\begin{tabular}{|c|c|c|c|}
\hline Sex & Group I & Group II & Total \\
\hline Male & 15 & 18 & 33 \\
\hline Female & 6 & 3 & 9 \\
\hline Total & 21 & 21 & 42 \\
\hline
\end{tabular}

In our study, there were $33(78.57 \%)$ male and 9 (21.43\%) female patients present. In group I, $15(35.72 \%)$ males and $6(14.28 \%)$ female patients had undergone surgery. In group II $18(42.87 \%)$ male and $3(7.13 \%)$ female patients had undergone surgery.

\section{Mode of injury}

Table 3: Mode of trauma to patients

\begin{tabular}{|c|c|c|c|}
\hline Mode of trauma & Group I & Group II & Total \\
\hline Fall from height & 12 & 10 & $22(52.39 \%)$ \\
\hline Road traffic accident & 3 & 4 & $7(16.67 \%)$ \\
\hline Fall at home & 2 & 3 & $5(11.9 \%)$ \\
\hline Assault & 1 & 1 & $2(4.76 \%)$ \\
\hline Sport related injury & 3 & 3 & $6(14.28 \%)$ \\
\hline
\end{tabular}


In our study, we had $22(52.39 \%)$ patients who had sustained trauma due to fall from height, 7 (16.67\%) patients with Road Traffic Accident, 5 (11.9\%) patients due to fall at home, 2 $(4.76 \%)$ had Assault and 6(14.28\%) had Sport related injury.

\section{Type of fracture}

Table 4: Morphology of fractures AO type

\begin{tabular}{|c|c|c|}
\hline Essex-Lopresti type & Group I & Group II \\
\hline Joint depression & $17(80.95 \%)$ & $15(71.42 .95 \%)$ \\
\hline Tongue type & $4(19.04 \%)$ & $6(28.57 \%)$ \\
\hline
\end{tabular}

Intra and post operative variable including complications

Table 5: Different intra and post-operative variables

\begin{tabular}{|c|c|c|}
\hline Variables & Group I & Group II \\
\hline Mean Pre-operative Bohler's angle & $10.08^{0}$ & $10.95^{0}$ \\
\hline Mean Post-operative Bohler's angle & $29.08^{0}$ & $21.43^{0}$ \\
\hline Mean Bohler's angle at the time of Union & $28.43^{0}$ & $18.26^{0}$ \\
\hline Mean Partial weight bearing (weeks) & 6.47 & 6.61 \\
\hline Mean Full weight bearing (months) & 3.09 & 3.95 \\
\hline Mean Union (weeks) & 10.39 & 11.95 \\
\hline Delayed wound healing & 3 & 3 \\
\hline Superficial wound infection & 0 & 1 \\
\hline Painful hardware & 0 & 1 \\
\hline Sural nerve complication & 0 & 1 \\
\hline Mean operating time & 105.14 & 90.15 \\
\hline
\end{tabular}

In Group I patients treated with iliac crest bone grafting, partial weight bearing was started in 6-8 weeks and full weight bearing in 3- 6 months.18 patients $(85.71 \%)$ started full weight bearing in 3-month duration, while 3 patients (14.28\%) took 4-6 months due to delayed wound healing. The time for union was $8-14$ wks. In 20 cases (95.65\%) normal Bohler's angle (i.e. $20^{\circ}-40^{\circ}$ ) was achieved. There were 3 cases (13.04\%) of post-operative delayed wound healing. All healed with daily dressing and delayed mobilization within 3 weeks and had no further treatment. None of the patients developed severe infection. None of the patient developed sural nerve complication in the form of loss of sensation on lateral aspect of foot or had painful hardware.

In group II patients treated without bone graft, partial weight bearing was started within 6-8 weeks and full weight bearing was started within 3- 6 months.10 patients (47.61\%) started full weight bearing in 3-month duration, while 11 patients $(52.38 \%)$ took 4-6 months due to delayed wound healing. The average time for union was $10-16$ wks. In 17 cases $(73.91 \%)$ normal Bohler's angle (i.e. $20^{\circ}-40^{\circ}$ ) was achieved. There were 3 cases $(13.04 \%)$ of post-operative delayed wound healing. All healed with daily dressing and delayed mobilization within 3 weeks and had no further treatment. 1 patient $(4.76 \%)$ had superficial wound infection and treated with oral antibiotics. None of the patients developed severe infection. 1 patient $(4.76 \%)$ developed sural nerve complication in the form of loss of sensation on lateral aspect of foot and 1 patient $(4.76 \%)$ had painful hardware, so implant removal was done after bony union.

\section{Evaluation of results}

The functional outcome was assessed by American ankle and foot score (AOFAS) (Table 6). In our study, $12(57.14 \%)$ patients had excellent, $6(28.58 \%)$ patients had good, 2
$(9.52 \%)$ had fair and $1(4.76 \%)$ patients had poor functional outcome in Group I. In group II, 8 (38.09\%) patients had excellent, $7(33.33 \%)$ patients had good and $5(23.80 \%)$ patients had fair outcome and $1(4.71 \%)$ patient had poor functional outcome.

Table 6: Outcome of patients in both groups

\begin{tabular}{|c|c|c|}
\hline Aofas & Group I & Group II \\
\hline Excellent & $12(57.14 \%)$ & $8(38.09 \%)$ \\
\hline Good & $6(28.58 \%)$ & $7(33.33 \%)$ \\
\hline Fair & $2(9.52 \%)$ & $5(23.80 \%)$ \\
\hline Poor & $1(4.76 \%)$ & $1(4.71 \%)$ \\
\hline
\end{tabular}

Demographic characteristics of the study group were summarized with means and standard deviations (SDs) for interval level variables and with percentages for categorical variables (Table $7,8,9,10,11,12,13$ ). Normal ranges for differences were established as within $95 \%$ confidence interval; the Gaussian approximations of the means \pm 1.96 SDs were also calculated. A chi-square test $(\chi 2)$ test was used for the analysis of categorical variables. Comparison with two groups was done by $t$ test for continuous variable and chisquare test for categorical variable. A p value of less than 0.05 was considered statistically significant.

Group I: Surgery with bone grafting

Table 7: Paired Samples Statistics

\begin{tabular}{|c|c|c|c|c|}
\hline $\begin{array}{c}\text { Group } \\
\text { I }\end{array}$ & $\begin{array}{c}\text { Mean Bohler's } \\
\text { angle }\end{array}$ & N & $\begin{array}{c}\text { Std. } \\
\text { Deviation }\end{array}$ & $\begin{array}{c}\text { Std. Error } \\
\text { Mean }\end{array}$ \\
\hline pre-op & 9.52 & 21 & 3.763 & 0.821 \\
\hline post-op & 28.90 & 21 & 5.873 & 1.282 \\
\hline
\end{tabular}

Table 8: Paired Samples Correlations

\begin{tabular}{|c|c|c|c|}
\hline Group I & N & Correlation & Sig. \\
\hline pre-op and post-op & 21 & 0.500 & 0.021 \\
\hline
\end{tabular}

$\mathrm{P}$ value is $<0.05$ i.e. 0.021 , suggesting there is significant difference in Bohler's angle before and after surgery. At 20 degrees of freedom, 5\% significant limit of $t$ is 2.09 . The observed $t$ value is 7.237 times the SE suggesting surgical management improves Bohler's angle.

Group II: Surgery with bone grafting

Table 9: Paired Samples Statistics

\begin{tabular}{|c|c|c|c|c|}
\hline $\begin{array}{c}\text { Group } \\
\text { II }\end{array}$ & $\begin{array}{c}\text { Mean Bohler's } \\
\text { angle }\end{array}$ & N & $\begin{array}{c}\text { Std. } \\
\text { Deviation }\end{array}$ & $\begin{array}{c}\text { Std. Error } \\
\text { Mean }\end{array}$ \\
\hline pre-op & 21.10 & 21 & 6.156 & 1.343 \\
\hline post-op & 10.95 & 21 & 2.906 & 0.634 \\
\hline
\end{tabular}

Table 10: Paired Samples Correlations

\begin{tabular}{|c|c|c|c|}
\hline Group II & $\mathbf{N}$ & Correlation & Sig. \\
\hline pre-op and post-op & 21 & 0.839 & 0.000 \\
\hline
\end{tabular}

$\mathrm{P}$ value is $<0.05$ i.e. 0.0001 , suggesting there is significant difference in Bohler's angle before and after surgery. At 20 degrees of freedom, $5 \%$ significant limit of $t$ is 2.09 . The observed $\mathrm{t}$ value is 11.50 times the SE suggesting surgical management improves Bohler's angle. 


\section{Group I and Group II}

Table 11: Paired Samples Statistics

\begin{tabular}{|c|c|c|c|c|c|}
\hline \multicolumn{2}{|c|}{} & Mean Bohler's angle & N & Std. Deviation & Std. Error Mean \\
\hline \multirow{2}{*}{ Pair 1 } & post-op I & 29.38 & 21 & 5.687 & 1.241 \\
\cline { 2 - 6 } & post-op II & 21.10 & 21 & 6.156 & 1.343 \\
\hline
\end{tabular}

Table 12: Paired Samples Correlations

\begin{tabular}{|c|c|c|c|c|}
\hline \multicolumn{2}{|c|}{} & N & Correlation & Sig. \\
\hline Pair 1 & post-op I and post-op II & 21 & -0.165 & 0.474 \\
\hline
\end{tabular}

Table 13: Paired Samples Test

\begin{tabular}{|c|c|c|c|c|c|c|c|c|}
\hline \multicolumn{9}{|c|}{ Paired Samples Test } \\
\hline & \multicolumn{5}{|c|}{ Paired Differences } & \multirow[b]{3}{*}{$\mathrm{t}$} & \multirow[b]{3}{*}{ df } & \multirow[b]{3}{*}{ Sig. (2-tailed) } \\
\hline & \multirow[b]{2}{*}{ Mean } & \multirow[b]{2}{*}{ Std. Deviation } & \multirow{2}{*}{$\begin{array}{l}\text { Std. Error } \\
\text { Mean }\end{array}$} & \multicolumn{2}{|c|}{$\begin{array}{l}\text { 95\% Confidence Interval of the } \\
\text { Difference }\end{array}$} & & & \\
\hline & & & & Lower & Upper & & & \\
\hline Pair 1 post-op A - post-op B & 8.286 & 9.045 & 1.974 & 4.168 & 12.403 & 4.198 & 20 & .000 \\
\hline
\end{tabular}

At 20 degrees of freedom, 5\% significant limit of $t$ is 2.09 . The observed $\mathrm{t}$ value is 4.198 times the $\mathrm{SE}$ suggesting Bohler's angle correction in Group I is better than Group II.

\section{Discussion}

The treatment of calcaneal fracture has long been major topic of debate. CT scan with 3D reconstruction provided improved understanding of calcaneal fractures and led to a clinically relevant classification of these injuries ${ }^{[4]}$. The therapeutic modalities for displaced intra-articular calcaneal fractures can be divided into conservative and operative management. The latter comprises both the open reduction and internal fixation (ORIF) and percutaneous reduction and internal fixation (PRIF). ORIF is considered the gold standard treatment for displaced intra articular fractures of the calcaneum by most experts, as it generally provides overall good to excellent results and the ability to anatomically restore the subtalar joint [5]. Good results are achieved if the stable anatomical reduction of the posterior facet is possible. Several open surgical techniques have been described in the past, of which the extended lateral approach has been applied most frequently ${ }^{[6]}$. Alternative operative techniques include a medial approach, plantar approach, combined lateral and medial approach, limited posterior approach, and the sinus tarsi approach ${ }^{[7]}$. The results of ORIF and conservative treatment have been described and compared in several studies. These studies show improved outcome after operative treatment in subgroups and a higher rate of failed initial treatment with an increased need for a subtalar arthrodesis in conservatively treated patients ${ }^{[8]}$. The restoration of the tension of the plantar fascia by reconstruction of Bohler's angle and hind foot length is important for the biomechanics of the foot ${ }^{[9]}$. Special plates have been invented for the treatment of calcaneal fractures (e.g. AO calcaneal plate, Galveston plate, low contact plate). The selected implant should be able to neutralize the forces resulting from the Achilles tendon and maintain reduction of the fragments until bony consolidation.

Incidence and severity of post-traumatic subtalar arthritis depends on the fracture type, calcaneal shape, and position after the osteosynthesis, chondral injury of the subtalar joint, and articular facet congruency. The treatment of calcaneal fractures is complex and has to be individualized depending on patient characteristics, fracture type and the condition of the soft tissues. While most of the surgeons while operating intra articular calcaneal fractures would want to achieve anatomical intra articular reduction, much less attention is paid to Bohler's tuber joint angle. A calcaneal fracture will result in a significant decrease or loss of the Bohler's angle [10]. At present, there is only a limited amount of data available on predicting the functional outcome after open reduction internal fixation of calcaneal fractures. The purpose of this study was to evaluate the correlation between Bohler's angle and functional outcome in displaced intra-articular calcaneal fractures treated with internal fixation, with or without bone grafting.

In our study, after evaluating a results, treatment of calcaneal Fractures requires following considerations, we evaluated each fracture radiologically for displacement of fragments and preoperatively decided about type of plate and number of screws. This preoperative planning helped us a lot while operating in theatre. We classified the fractures according to Essex-Loprasti classification ${ }^{[11]}$. We agree with Parmar HV et al. [12] that compared to conservatively treated patients improved outcome is seen with patient managed surgically. In our study we observed lesser infection rate in bone graft group than without bone graft group but there is concern of donor site morbidity associated with iliac crest bone graft. We agree with Palmer I ${ }^{[13]}$. that Restoration of bohler's angle was associated with better outcome. In our study post-operative bohler's angle was significantly higher in bone graft group. Restoration of bohler's angle was statistically significant in the bone graft group than in a group without bone graft. We have confirmed that in treatment of intraarticular calcaneal fractures bone graft augmentation could restore the bohler's angle better and prevent late collapse. We agree with B Kienast et al. ${ }^{[14]}$ that patients with bone grafts could return to full weight bearing earlier compared to group without bone grafting.

According to Abidi M. et al. ${ }^{[15]}$ anatomic reduction of the fracture is necessary to get good functional outcome. Early range of motion should be started after giving adequate, stability and alignment with fixation. We also agree B Kienast et al. ${ }^{[16]}$ that early motion is necessary in order to obtain good result. Stiffness is usually the result of immobilization. In surgically treated patient mobilization should begin within 4 to 6 weeks. This, however, should not be carried out at the expense of the reduction or at the expense of wound healing. If any doubt exists as to the stability of fixation, then mobilization should begin either in a cast brace or begin in a cast brace from the start of motion post operatively. We also found that, mechanism of injury determines the type of 
fracture. In case of simple falls, mainly type I fractures were found commonly. In case of motorcycle accidents, mainly type II fracture pattern found ${ }^{[17]}$. Seven of our patients had problems with wound healing or infection. Out of which only one patient developed superficial skin infection, which settled with dressing. This can be attributed to a smaller incision and exposure and hence a shorter surgical and tourniquet time ${ }^{[18]}$. The principles of ORIF for calcaneal fracture have been elaborately elucidated by Edward J. Harvey et al. ${ }^{[19]}$ They have advocated the use of contoured plates (for improved mechanical leverage) and fewer screws (to avoid unnecessary bone and soft tissue damage). In fact, filling off each and every hole can weaken the bone and it may refracture on implant removal (Michael Q. Potter et al.) ${ }^{[20]}$.

\section{Conclusion}

In our prospective study of 42 cases of calcaneal fractures treated with ORIF with plating, with or without bone grafting, following conclusions we have drawn.

1) Restoration of Bohler's angle is key to achieve good result in displaced calcaneal fractures.

2) Autologous bone graft is beneficial in achieving and maintaining normal Bohler's angle in displaced calcaneal fractures.

3) Peak age group for calcaneal Fractures is 30-40 years, which are mainly involved in trauma due to fall from height.

4) Vehicular accidents can also be giving rise to indirect trauma due to abnormal loading.

5) Soft tissue injuries are commonly seen in high energy pattern, especially those having direct injury.

6) Incidence of wound complications can be minimised with the smaller incision, shorter surgical and tourniquet time.

Finally, we conclude with, in view of the excellent results obtained with this technique, we advocate the use of Bohler's angle as a key to achieve excellent result in displaced calcaneal fractures and also use of autologous bone graft in achieving and maintaining normal Bohler's angle.

\section{Declaration \\ Conflicts of interest: None declared \\ Funding: None \\ Ethical approval: not required}

\section{Acknowledgement}

We would like to acknowledge residents of radiology for contributing for this case series. Also lab and $\mathrm{x}$ ray technicians whose sincere effort made this case report possible.

\section{Abbreviations}

ORIF (Open reduction and internal fixation), CT (computerised tomography), PRIF (percutaneous reduction and internal fixation).

\section{References}

1. Aditya Daftary, Andrew Haims H, Michael Baumgaertner R. Fractures of the Calcaneus: A Review with Emphasis on CT: Radio Graphics, 2005; 25:12151226.

2. Lindsay WRN, Dewar FP. Fractures of the os calcis. Am J Surg. 1958; 95:555-576.

3. Bohler L. Diagnosis, pathology and treatment of fractures of the os calcis. J Bone Joint Surg. 1931; 13:75-89.
4. Crosby LA, Fitzgibbons T. Computerized tomography scanning of acute intra-articular fractures of the calcaneus. J Bone Joint Surg. 1990; 72:852-859.

5. Zeman P, Zeman J, Matejka J, Koudela K. Long-term results of calcaneal fracture treatment by open reduction and internal fixation using a calcaneal locking compression plate from an extended lateral approach. Acta Chir Orthop Traumatol Cech. 2008; 75(6):457-64.

6. Cavadas PC, Landin L. Management of soft-tissue complications of the lateral approach for calcaneal fractures. Plast Reconstr Surg. 2007; 120(2):459-466.

7. Brunner UH, Betz A, Halama R. A The surgical treatment of calcaneus fractures. Orthopade, 2001; 20(1):55-66.

8. Howard JL, Buckley R, McCormack R, Pate G, Leighton $\mathrm{R}$, Petrie D et al. Complications following management of displaced intra-articular calcaneal fractures: a prospective randomized trial comparing open reduction internal fixation with non-operative management. J Orthop Trauma. 2003; 17:241-9.

9. Loucks C, Buckley R. Bohler's angle: correlation with outcome in displaced intra-articular calcaneal fractures. J Orthop Trauma. 2001; 15(8):594.

10. Bajammal S, Tornetta P 3rd, Sanders D, Bhandari M. Displaced intra-articular calcaneal fractures. J Orthop Trauma. 2005; 19:360-4.

11. Essex Lopresti P. The mechanism, reduction technique, and results in fractures of the os calcis. Br J Surg. 1952; 39:395-419.

12. Parmar HV, Triffitt PD, Gregg PJ. Intra-articular fractures of the calcaneum treated operatively or conservatively: a prospective study. J Bone Joint Surg. Br. 1993; 75:932-937.

13. Palmer I. The mechanism and treatment of fractures of the calcaneus. J Bone Joint Surg Am. 1948; 30:2-8.

14. Yang et al. Intra-articular calcaneal fractures with or without bone grafts; A systematic review of literature. Indian jrnl orthp, 2012; 46:130-7.

15. Abidi NA, Dhawan S, Gruen GS, Vogt MT, Conti SF. Wound-healing risk factors after open reduction and internal fixation of calcaneal fractures. Foot Ankle Int. 1998; 19(12):856-861.

16. Kienast B, Gille J, Queitsch C, Kaiser MM, Thietje R, Juergens C. Early Weight Bearing of Calcaneal Fractures Treated by Intraoperative 3D-Fluoroscopy and LockedScrew Plate Fixation. Open Orthop J. 2009; 3:69-74.

17. Sanders R. Displaced intra-articular fractures of the calcaneus. J Bone Joint Surg (Am). 2000; 82(2):225-250.

18. Koski A, Kuokkanen H, Tukiainen E. Post-operative wound complication after internal fixation closed calcaneal fracture. Scandinavian Journal of Surgery. 2005; 94:243-245.

19. Edward Harvey J, Leslie Grujic, John Early S, Stephen Benirschke K, Bruce Sangeorzan J. Morbidity Associated with ORIF of Intra-Articular Calcaneus Fractures Using a Lateral Approach. Foot \& Ankle International, 2001, 22.

20. Michael Potter Q, James Nunley A. Long-Term Functional Outcomes after Operative Treatment for IntraArticular Fractures of the Calcaneus the Journal of Bone \& Joint Surgery. 2009; 91:8. 